\title{
Structural Modification of Ibuprofen as new NSAIDs via DFT, Molecular Docking and Pharmacokinetics Studies
}

\author{
Oluwatoba Emmanuel OYENEYIN ${ }^{1}$ iD, Nureni IPINLOJU ${ }^{1}$ iD, Nathanael Damilare OJO $^{2}$ iD, \\ Daniel Dada AKERELE ${ }^{1}$ \\ ${ }^{I}$ Theoretical and Computational Chemistry Unit, Department of Chemical Sciences, Adekunle Ajasin University, \\ Akungba-Akoko, Ondo State, Nigeria \\ ${ }^{2}$ Department of Chemistry, University of Ibadan, Oyo State, Nigeria.
}

\begin{abstract}
Inflammations generate uneasiness. Multiple drug resistance imposes restrictions on the effectiveness of most existing drugs which necessitates either novel drug design or systematic derivatization of existing ones. This study adopts quantum mechanical and molecular docking approach to model and explore twenty derivatives of ibuprofen as potential non-steroidal antiinflammatory drug candidates in order to improve and update existing NSAIDs database, and alleviate global multiple drug resistance challenge taking ibuprofen as the standard. Optimization and calculation of the drug-like quantum chemical parameters of the compounds were conducted at DFT/B3LYP/6-31G* level of theory. Binding affinity, interaction and inhibition of the potential drug-candidates with human cyclooxygenase (COX-2) receptor were investigated using molecular docking studies. Pharmacokinetic properties were studied. The drug candidates interact effectively and spontaneously with the COX-2 receptor via hydrogen bonding and $\pi-\pi$ stacking with greater binding affinity than ibuprofen except compounds 5 and 18. The energy gap, global hardness and softness, and chemical potential of the derivatives suggest that they are kinetically unstable, more chemically reactive than the parent drug and are effective electron donors. The docking studies show that compound 7 (3-(4-(3,3,3-trifluoro-2-methylpropyl)phenyl)butan-2-one) displays remarkably high binding affinity to the amino acid residues, ASN382 and HIS207, via H-bonding and $\pi-\pi$ stacking interactions, respectively. From the pharmacokinetic studies, all the derivatives are not substrates to permeability glycoprotein (suggesting reduced therapeutic failure), not efficiently permeable to skin, can be absorbed by human intestine and can cross the blood brain barrier. Some derivatives are potential CYP1A2, CYP2D6 and CYP3A4 inhibitors. All the ibuprofen derivatives exhibit comparable drug-likeness with standard.
\end{abstract}

Keywords: Non-steroidal anti-inflammation drugs; COX-2 inhibitors; Ibuprofen; Density functional theory; Molecular docking; Pharmacokinetics properties.

\section{INTRODUCTION}

Non-steroidal anti-inflammation drugs (NSAIDs) are a drug category that reduces fever, pain, headache, stiffness and inflammation [1,2]. They are mostly used to treat acute and chronic conditions where pain and inflammation occur [1,3]. NSAIDs work effectively by blocking the cyclooxygenase (COX-1 and COX-2) enzymes, which is responsible for the synthesis of prostaglandin via arachidonic acid pathway, thereby reduces the synthesis of prostaglandin in the body [3-5]. Ibuprofen, a propionic acid derivative, is a class of NSAIDs that is widely used as an anti-inflammatory [6] and analgesic [7] agent. It can also be used in the treatment of cancer [8]. Some common side effects of ibuprofen are aggravated asthma, nausea, indigestion and abdominal pain, constipation or diarrhea $[2,9]$. Drug discovery and development is a time consuming and expensive process. Modifying existing drugs provides an easy way to rapidly develop novel drugs with improved activity and overcome problems like resistance and allergies associated with existing ones. Structural modification is an alteration of a known lead compound by introducing some substituents into its architecture.

Computer aided drug design (CADD) is a contemporary way of developing new therapeutic lead compounds. It is cost-effective, time saving, helps in understanding experimental findings and probes into the mechanism and atomistic details of molecules and receptors. Density Functional Theory (DFT) is a popular quantum chemical method employed to investigate molecular properties [10-13]. Molecular docking helps to predict the interaction of molecules (ligand) in the active site of the enzyme (receptor) [14,15]. It is also used to identify different binding modes in a protein binding site [16,17]. Investigating the pharmacokinetics helps in predicting the effect, fate and safety of a compound after administration in human body. Recent investigations have been conducted on antiinflammatory and pharmacological properties of ibuprofen and some of its derivatives using DFT and molecular docking approaches. Careful modification of the propionic acid, aryl and/or the isobutyl moieties of ibuprofen have been found to improve the anti-inflammatory, hepatotoxic and molecular properties of the drug candidates $[18,19]$. 
In this study, ibuprofen and its modified analogues were investigated for their pharmacological activities via density functional theory, molecular docking and pharmacokinetics studies. The physico-chemical properties of these compounds were calculated via DFT method, the molecules were docked into the active site of human cyclooxygenase- 2 receptor, $5 \mathrm{~F} 1 \mathrm{~A}$.

\section{METHODOLOGY}

\subsection{DFT calculations}

The structures of the molecules (table 1, Figure 2) were optimized using DFT method with hybrid Becke threeparameter Lee, Yang and Parr (B3LYP) correlation [20] and a 6-31G* basis having initially searched for the molecules' most stable conformers via molecular mechanics force field, all with Spartan 14 computational chemistry software on an intel (R) computer with $2.60 \mathrm{GHz}, 6.00 \mathrm{~GB}$ RAM. Molecular parameters such as energies of the frontier molecular orbitals, that is, the highest occupied molecular orbital ( $\left.\mathrm{E}_{\text {Hомо }}\right)$ and lowest unoccupied molecular orbital ( $\mathrm{E}_{\mathrm{LUMO}}$ ) were computed at this level of theory. Energy band gap, $\Delta \mathrm{E}$ (eq. 1), chemical hardness, $\eta$ (eq. 2), chemical softness, $\delta$ (eq. 3 ) and chemical potential, $C_{P}$ (eq. 4) were calculated from $\mathrm{E}_{\mathrm{HOMO}}$ and $\mathrm{E}_{\mathrm{LumO}}$. Lipophilicity $(\log \mathrm{P})$, polar surface area $(\mathrm{PSA})$, polarizability, hydrogen bond donor (HBD) and hydrogen bond acceptor (HBA) were also computed.

$$
\begin{aligned}
\Delta E & =\mathrm{E}_{\text {LUMO }}-\mathrm{E}_{\text {HOMO }} \\
\eta & =\frac{\Delta E}{2} \\
\delta & =\frac{1}{\eta} \\
\mathrm{C}_{\mathrm{P}} & =\frac{E_{H O M O}+E_{L U M O}}{2}
\end{aligned}
$$

\subsection{Molecular docking study}

\subsubsection{Protein preparation}

The crystallized three-dimensional structure of salicylate bounded human cyclooxygenase-2 receptor, an oxidoreductase inhibitor in Homo sapiens (PDB ID: 5F1A; resolution $2.38 \AA$ ) was downloaded in pdb format from protein data bank [21] (figure 1). It was prepared with Schrodinger Suite 2017-1 interface using protein preparation wizard [22]. The protein was prepared by removing interfering ligand, assigning bond order and charges, deleting water molecules and removing all heteroatom. Furthermore, tautomeric states were generated at $\mathrm{pH} 7.0 \pm 2$ using Epik [23] and the protein energy minimization was carried out using OPLS3 force field [24].

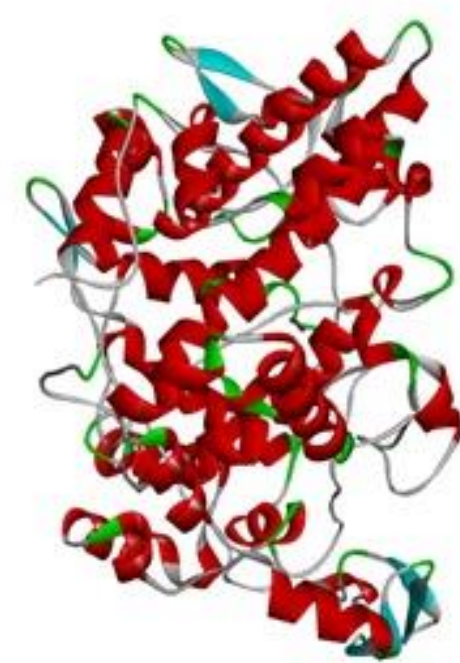

Figure 1: 3D Crystal Structure of Receptor, 5F1A

\subsubsection{Ligands preparation}

The optimized structures were imported and prepared using ligprep module in Schrodinger Suite 2017-1 via OPLS3 force field. The generation of possible ionization and tautomeric states were achieved using Epik at $\mathrm{pH}$ of $7.0 \pm 2$

\subsubsection{Molecular docking and visualization}

Molecular docking was done to predict the interaction, binding affinity and to understand the mechanism of COX-2 inhibition by newly modeled molecules. The prepared ligands were dock into the active site ( $\mathrm{x}=$ $29.99, y=34.57, z=238.89$ ) of prepared human prostaglandin synthase protein $(5 \mathrm{~F} 1 \mathrm{~A})$ via glide docking [25] in Schrodinger Suite 2017-1. The interaction and visualization diagrams were viewed via ligand interaction tools.

\subsection{Computational Pharmacokinetics}

SwissADME [26], an online web tool used in predicting the pharmacokinetics and drug likeness of small compound was employed in testing the druglikeness of the newly modeled molecules and ibuprofen. The chemical structure of each molecule was input in SMILES (simplified molecular-input lineentry system) format to generate their pharmacokinetics properties.<smiles>[R3]C(=O)C(C)c1ccc(CC([R3])C)c([R6])c1</smiles>

Figure 2: Structure of Ibuprofen Derivatives 
Table 1: Chemical structures of ibuprofen and its modified derivatives

\begin{tabular}{|c|c|c|c|}
\hline Compounds & $\mathrm{R}_{1}$ & $\mathrm{R}_{2}$ & $\mathrm{R}_{3}$ \\
\hline Ibuprofen & $\mathrm{CH}_{3}$ & $\mathrm{H}$ & $\mathrm{OH}$ \\
\hline 1 & $\mathrm{CH}_{3}$ & $\mathrm{H}$ & $\mathrm{NH}_{2}$ \\
\hline 2 & $\mathrm{CH}_{3}$ & $\mathrm{H}$ & $\mathrm{OCH}_{3}$ \\
\hline 3 & $\mathrm{CH}_{3}$ & $\mathrm{H}$ & $\mathrm{CH}_{2} \mathrm{OH}$ \\
\hline 4 & $\mathrm{CH}_{3}$ & $\mathrm{H}$ & $\mathrm{CH}_{2} \mathrm{NH}_{2}$ \\
\hline 5 & $\mathrm{CF}_{3}$ & $\mathrm{H}$ & $\mathrm{OH}$ \\
\hline 6 & $\mathrm{CH}_{2} \mathrm{OH}$ & $\mathrm{H}$ & $\mathrm{CH}_{3}$ \\
\hline 7 & $\mathrm{CF}_{3}$ & $\mathrm{H}$ & $\mathrm{CH}_{3}$ \\
\hline 8 & F & $\mathrm{OCH}_{3}$ & $\mathrm{OH}$ \\
\hline 9 & $\mathrm{CH}_{3}$ & $\mathrm{NH}_{2}$ & $\mathrm{OH}$ \\
\hline 10 & $\mathrm{NHCOCH}_{3}$ & $\mathrm{H}$ & $\mathrm{CH}_{3}$ \\
\hline 11 & $\mathrm{OCH}_{3}$ & $\mathrm{H}$ & $\mathrm{NH}_{2}$ \\
\hline 12 & $\mathrm{OCH}_{3}$ & $\mathrm{H}$ & $\mathrm{CH}_{3}$ \\
\hline 13 & $\mathrm{CH}_{3}$ & $\mathrm{COOH}$ & $\mathrm{CH}_{3}$ \\
\hline 14 & $\mathrm{CH}_{3}$ & $\mathrm{H}$ & $\mathrm{CH}_{2} \mathrm{CH}_{3}$ \\
\hline 15 & $\mathrm{CH}_{3}$ & $\mathrm{OH}$ & $\mathrm{CH}_{2} \mathrm{CH}_{3}$ \\
\hline 16 & $\mathrm{CH}_{3}$ & $\mathrm{NHCOCH}_{3}$ & $\mathrm{CH}_{2} \mathrm{CH}_{3}$ \\
\hline 17 & $\mathrm{CH}_{3}$ & $\mathrm{CF}_{3}$ & $\mathrm{OH}$ \\
\hline 18 & $\mathrm{CH}_{3}$ & $\mathrm{H}$ & $\mathrm{OCH}_{2} \mathrm{CH}_{3}$ \\
\hline 19 & $\mathrm{CH}_{3}$ & $\mathrm{~F}$ & $\mathrm{OH}$ \\
\hline 20 & $\mathrm{CH}_{3}$ & $\mathrm{H}$ & $\mathrm{CH}_{2} \mathrm{~F}$ \\
\hline
\end{tabular}

\section{RESULTS AND DISCUSSION}

\subsection{DFT results}

\subsubsection{Frontier Molecular Orbital}

The molecular descriptors obtained such as the $\mathrm{E}_{\mathrm{HOMO}}$,

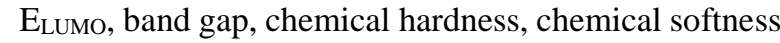
and other descriptors are tabulated in Table 2 and Table 3. These descriptors were used to predict the reactivity of ibuprofen and its modified derivatives. The energies of the FMOs (table 2) are important in determining the electronic structure of a compound. They are used to study the chemical reactivity, stability and transfer of electron in a molecule. The $\mathrm{E}_{\mathrm{HOMO}}$ is related to the ionization energy which represents the area with rich electron density, indicating the ability to donate electron to nearby molecule. The higher the $\mathrm{E}_{\text {номо }}$ of a molecule, the greater its potential to donate an electron. $\mathrm{E}_{\mathrm{LUMO}}$ represents the electron affinity, the area with lowest electron density, indicating the ability to accept electron from nearby molecule. The lower the $\mathrm{E}_{\mathrm{LUMO}}$ of a molecule, the more it is capable of accepting electron. Hence, higher $\mathrm{E}_{\text {HOMO }}$ and lower $\mathrm{E}_{\mathrm{LumO}}$ are responsible for high chemical reactivity, low stability and the ease with which the electron flow in a molecule would be [27-29]. The $\mathrm{E}_{\text {Hомо }}$ for all the compounds range from $5.42 \mathrm{eV}$ to $-6.76 \mathrm{eV}$. With the exception of compounds $3,5,17$ and 19, other derivatives display higher $\mathrm{E}_{\text {Номо }}$ than ibuprofen which suggests their great electron donating potential. Furthermore, the significant destabilization of the HOMO of compound 9 relative to ibuprofen implies the higher electron donating ability of the former which, consequently, indicates its better interaction with the electrophilic center of the cyclooxygenase-2 receptor. Also, the $\mathrm{E}_{\mathrm{Lumo}}$ values for all compounds vary between $-0.7 \mathrm{eV}$ and $-0.08 \mathrm{eV}$. The notable relative stabilization of the lowest-energy vacant molecular orbital of compound 13 contributes majorly to its low band gap (enhanced kinetic instability and chemical reactivity) and its susceptibility to nucleophilic interactions with the active sites of COX-2 receptor. The energy band gap, $\Delta \mathrm{E}$, is the difference between $\mathrm{E}_{\mathrm{HOMO}}$ and $\mathrm{E}_{\mathrm{LUMO}}$. This gives an insight about the stability of a molecule. Lower band gap energy signifies lower stability and high reactivity of molecule while higher band gap energy signifies high stability and low reactivity [30]. All the modified compounds have lower band gap than ibuprofen $(6.14 \mathrm{eV})$ except for compounds 5 and 18. This implies that almost all the modified compounds are less stable and more reactive toward the receptor than ibuprofen. Compound 13 has the lowest band gap of $4.85 \mathrm{eV}$. Interestingly, attachment of a carboxylic acid group at R2 position possibly destabilizes the energy gap and improves the chemical reactivity of the potential drug candidate.

\subsubsection{Global reactivity descriptors}

Global reactivity descriptors (table 2) were calculated to gain a deep understanding of the stability and the reactivity of ibuprofen and its modified derivatives towards the target receptor. Chemical hardness and softness are related to chemical stability of molecule where higher chemical hardness and lower chemical softness translate to higher stability and lower reactivity [30]. The hardness and softness computed for all the studied compounds range from $2.43 \mathrm{eV}$ to 3.08 $\mathrm{eV}$ and $0.33 \mathrm{eV}$ to $0.41 \mathrm{eV}$ respectively. All the studied compound, except compounds 5 and 18, possess lower hardness and higher softness than ibuprofen, with compound 13 being the most reactive of them all. The modified compounds are therefore less stable and more reactive than ibuprofen. Furthermore, the electronegativity values calculated for all the compounds are higher than ibuprofen with compound 13 having the highest electronegativity indicating that all the compounds can attract electron easily than ibuprofen.

\subsubsection{HOMO map, LUMO map and Molecular electrostatic potential analysis}

The optimized structures, HOMO, LUMO and electrostatic potential maps of ibuprofen and its twenty derivatives are shown in Figures 3a to 3e, S1-S16. The HOMO and LUMO of the potential drug candidates are essentially delocalized over the molecular structure. This implies that the compounds possess electrondonating and electron-deficient regions and are susceptible to electrophilic and nucleophilic attack. The uneven distribution of charges on the molecules is also 
corroborated by the electrostatic potential map (Figures 3 a to $3 \mathrm{e}, \mathrm{S} 1-\mathrm{S} 16)$.

The electrostatic potential surface map enables visualization, analysis of charge distribution and also displays the area of nucleophilic and electrophilic region in a molecule [31]. The negative electrostatic potential (ESP) represented by red color shows the sites that are prone to electrophilic attacks. Positive region represented by blue color shows the site for nucleophilic attacks. The surface potential energies for all compound range from $-205.309 \mathrm{~kJ} / \mathrm{mol}$ to -142.988 $\mathrm{kJ} / \mathrm{mol}$ for low energy region and the high energy region range from $79.720 \mathrm{~kJ} / \mathrm{mol}$ to $258.876 \mathrm{~kJ} / \mathrm{mol}$.

Generally, the carbonyl groups and the phenyl ring are mapped red (and yellow) indicating their susceptibility to electrophilic attack while the alkyl groups are essentially subject to nucleophilic invasion. Compounds 5, 8, 9, 17 and 19 have $\mathrm{COOH}$ at similar position with ibuprofen. The carboxylic oxygen atoms of these compounds display negative ESP and could be possible sites of electrophilic addition. The replacement of hydroxylic part of the carboxylic acid with electron-rich $\mathrm{NH}_{2}$ in compounds 1 and 11 converts the amino end to a Lewis-acid center that is subject to nucleophilic attack. Furthermore, systematic substitution of the carboxylic $\mathrm{OH}$ with alkyl $(6,7,10,12,13,14,15$ and 16), alkoxy (compounds 2 and 18), alcohol (compound 3), alkylamine (compound 4) and alkyl halide (compound 20) moieties imposes asymmetric charge distribution and creates nucleophilic and electrophilic sites for effective interaction with the COX-2 inhibitor's active sites. Subsequent derivatization of R1 and R2 groups generates more binding sites.

Table 2: Chemical Parameters obtained from ibuprofen and its modified derivatives via DFT at the B3LYP/6-

$31 \mathrm{G}^{*}$ Level

\begin{tabular}{|c|c|c|c|c|c|c|c|}
\hline Compounds & $\mathrm{E}_{\text {номо }}(\mathrm{eV})$ & $\mathrm{E}_{\text {LuMo }}(\mathrm{eV})$ & $\Delta \mathrm{E}(\mathrm{eV})$ & $\eta(\mathrm{eV})$ & $\delta\left(\mathrm{eV}^{-1}\right)$ & $\chi(\mathrm{eV})$ & $\mathrm{C}_{\mathrm{P}}(\mathrm{eV})$ \\
\hline 1 & -6.32 & -0.22 & 6.10 & 3.05 & 0.327 & 3.27 & -3.27 \\
\hline 2 & -6.30 & -0.21 & 6.09 & 3.05 & 0.328 & 3.26 & -3.26 \\
\hline 3 & -6.49 & -0.91 & 5.58 & 2.79 & 0.358 & 3.70 & -3.70 \\
\hline 4 & -6.14 & -0.64 & 5.50 & 2.75 & 0.363 & 3.39 & -3.39 \\
\hline 5 & -6.64 & -0.48 & 6.16 & 3.08 & 0.325 & 3.56 & -3.56 \\
\hline 6 & -6.18 & -0.50 & 5.68 & 2.84 & 0.352 & 3.34 & -3.34 \\
\hline 7 & -6.34 & -0.64 & 5.70 & 2.85 & 0.351 & 3.49 & -3.49 \\
\hline 8 & -5.87 & -0.24 & 5.63 & 2.82 & 0.355 & 3.06 & -3.06 \\
\hline 9 & -5.42 & -0.08 & 5.34 & 2.67 & 0.375 & 2.75 & -2.75 \\
\hline 10 & -6.36 & -0.70 & 5.66 & 2.83 & 0.353 & 3.53 & -3.53 \\
\hline 11 & -6.27 & -0.14 & 6.13 & 3.07 & 0.326 & 3.21 & -3.21 \\
\hline 12 & -6.20 & -0.52 & 5.68 & 2.84 & 0.352 & 3.36 & -3.36 \\
\hline 13 & -6.30 & -1.45 & 4.85 & 2.43 & 0.412 & 3.88 & -3.88 \\
\hline 14 & -6.21 & -0.51 & 5.70 & 2.85 & 0.351 & 3.36 & -3.36 \\
\hline 15 & -5.90 & -0.54 & 5.36 & 2.68 & 0.373 & 3.22 & -3.22 \\
\hline 16 & -5.91 & -0.49 & 5.42 & 2.71 & 0.369 & 3.22 & -3.22 \\
\hline 17 & -6.76 & -0.76 & 6.00 & 3.00 & 0.333 & 3.76 & -3.76 \\
\hline 18 & -6.29 & -0.14 & 6.15 & 3.08 & 0.325 & 3.22 & -3.22 \\
\hline 19 & -6.44 & -0.45 & 5.99 & 2.99 & 0.334 & 3.45 & -3.45 \\
\hline 20 & -6.31 & -0.87 & 5.44 & 2.72 & 0.368 & 3.59 & -3.59 \\
\hline Ibuprofen & -6.37 & -0.23 & 6.14 & 3.07 & 0.326 & 3.30 & -3.30 \\
\hline
\end{tabular}



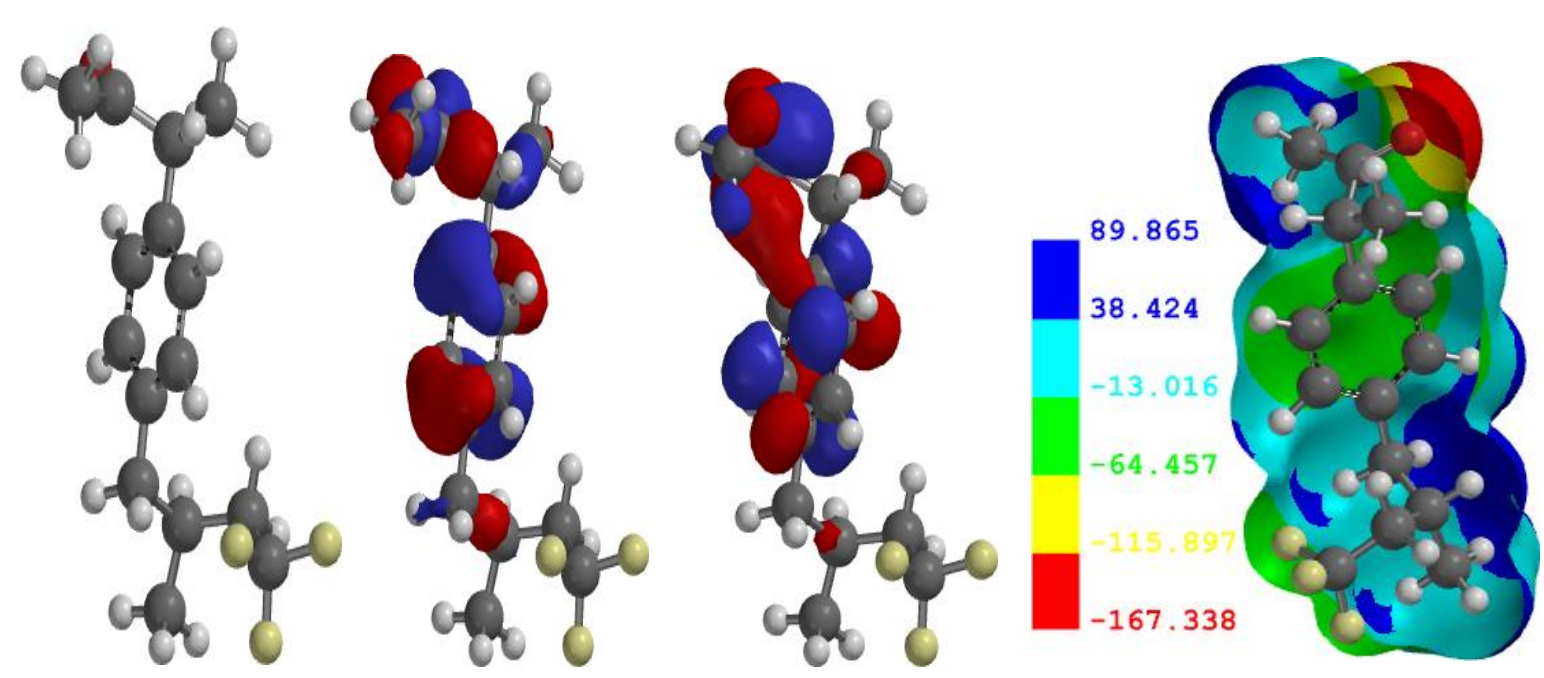

Figure 3a: Compound 7
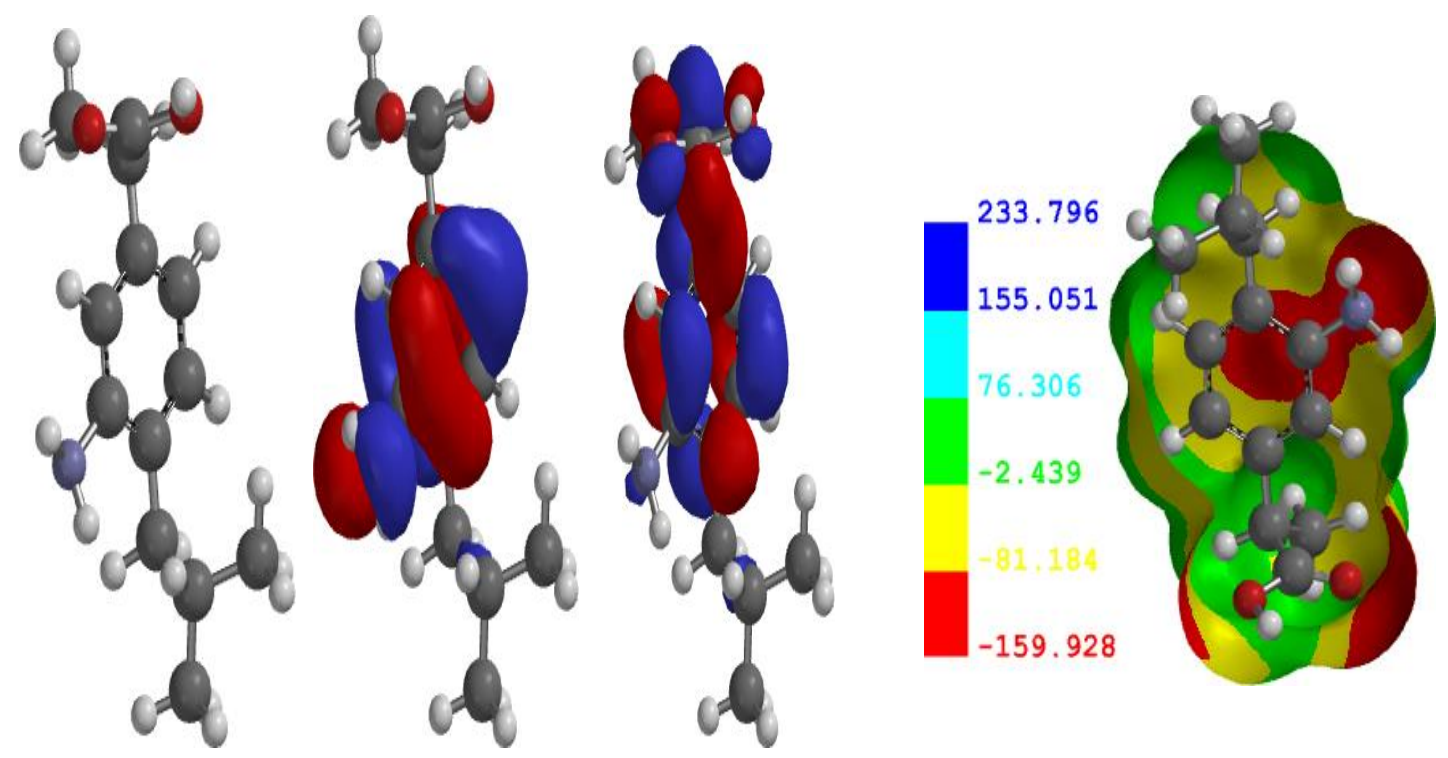

Figure 3b: Compound 9
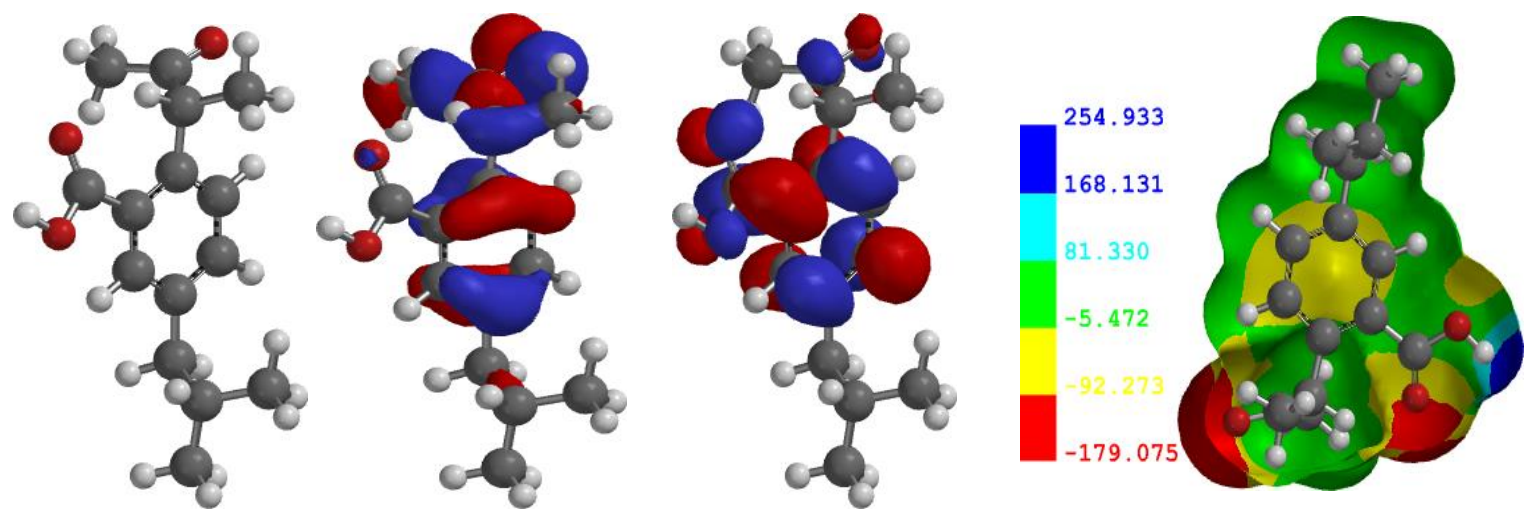

Figure 3c: Compound 13 


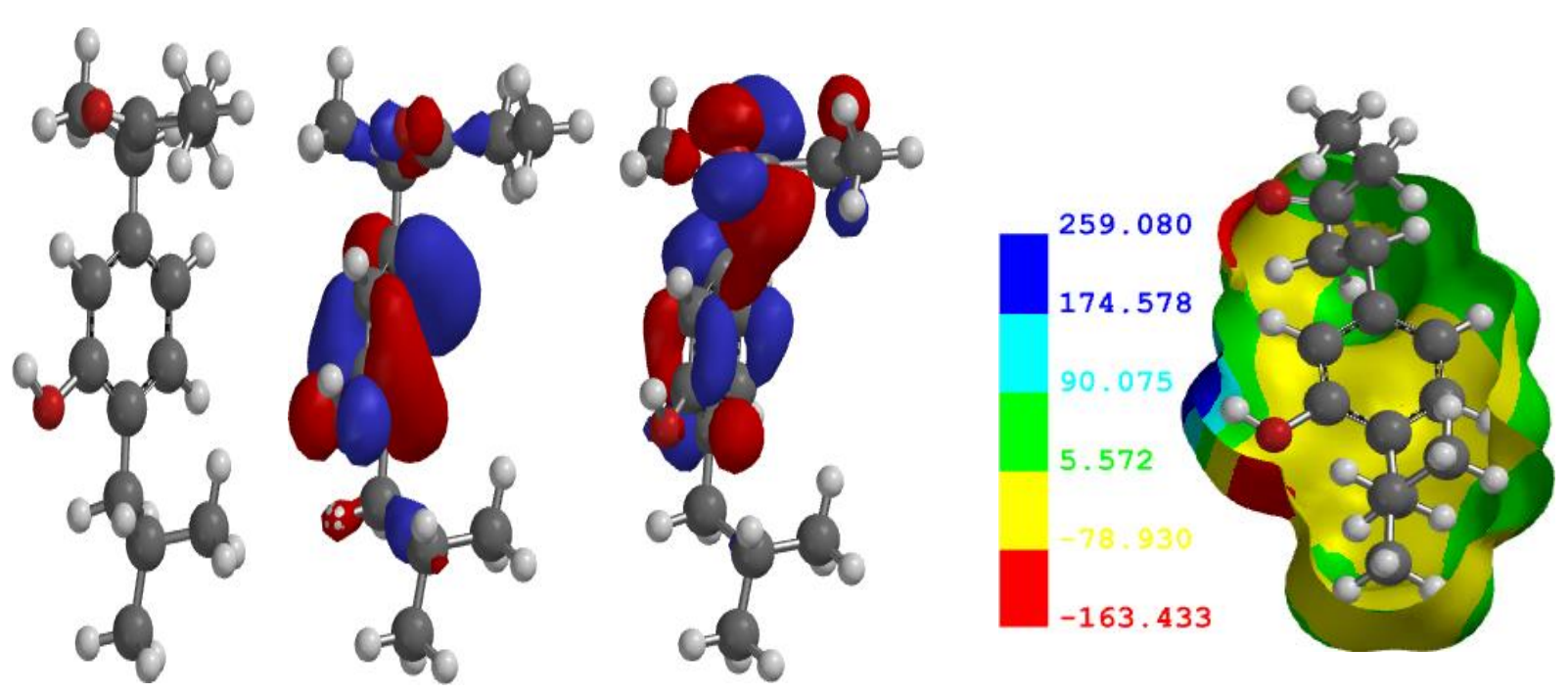

Figure 3d: Compound 15
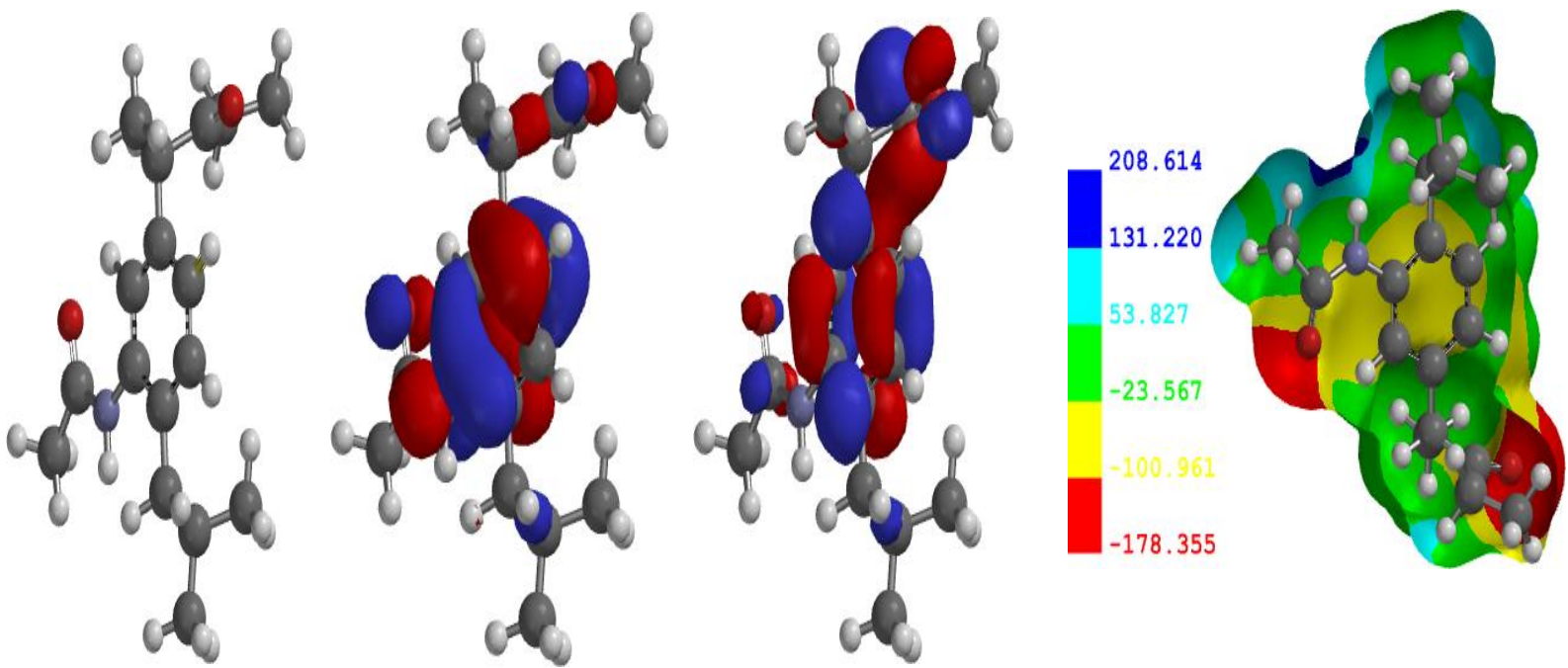

Figure 3e: Compound 16

Other vital molecular descriptors computed (Table3) are molecular weight (MW), polarizability, partition coefficient $(\log \mathrm{P})$, hydrogen bond donor (HBD), hydrogen bond acceptor (HBA) and polar surface area (PSA). These properties are important properties used in predicting drug likeness of a biologically active compound. The Lipinski rule of five (RO5) predicts that for a small molecule to be an orally active drug, it should possess the following properties: molecular mass should be less than $500, \log$, value should be less than or equal to 5, HBD should not be greater than 5 and HBA should be less than 10 (14) [32]. Violation of two or more of these properties indicate that the biologically active compound is not orally active. As can be seen in Table 3, all the modified compounds obey the Lipinski rule. This is indicative that all the modified compounds and ibuprofen are bioavailable. In addition, PSA is widely used for the potential of biological active compound to permeate cells. PSA not greater than $140 \mathrm{~A}^{2}$ and PSA not greater than $90 \mathrm{~A}^{2}$ is required for a compound to permeate cell membrane and blood brain barrier, respectively [33]. The PSA of all the modified compounds range from $14.416 \mathrm{~A}^{2}$ to $57.167 \mathrm{~A}^{2}$, showing that all the compound can permeate both cell membrane and can also penetrate blood brain barrier. 
Table 3: Chemical Parameters Obtained for ibuprofen and its modified derivatives via DFT at the B3LYP/6-

\begin{tabular}{|c|c|c|c|c|c|c|}
\hline \multicolumn{7}{|c|}{$31 \mathrm{G}^{*}$ Level } \\
\hline Compounds & MW & $\log \mathrm{P}$ & PSA $\left(A^{2}\right)$ & Polarizability & HBD & HBA \\
\hline Ibuprofen & 206.285 & 3.75 & 34.551 & 59.14 & 1 & 1 \\
\hline 1 & 205.301 & 3.10 & 38.290 & 59.41 & 1 & 2 \\
\hline 2 & 220.312 & 4.02 & 20.125 & 60.82 & 0 & 1 \\
\hline 3 & 220.312 & 3.52 & 32.057 & 60.77 & 1 & 2 \\
\hline 4 & 219.328 & 3.18 & 39.748 & 61.10 & 0 & 2 \\
\hline 5 & 260.255 & 4.12 & 34.564 & 60.26 & 1 & 1 \\
\hline 6 & 220.312 & 3.13 & 34.047 & 60.77 & 1 & 2 \\
\hline 7 & 272.310 & 4.97 & 14.416 & 62.76 & 0 & 1 \\
\hline 8 & 240.274 & 2.71 & 40.443 & 60.36 & 1 & 2 \\
\hline 9 & 221.300 & 2.95 & 57.167 & 60.14 & 2 & 2 \\
\hline 10 & 247.338 & 2.19 & 38.524 & 62.94 & 1 & 3 \\
\hline 11 & 235.327 & 2.33 & 45.198 & 61.64 & 1 & 3 \\
\hline 12 & 234.339 & 3.49 & 21.261 & 62.41 & 0 & 2 \\
\hline 13 & 248.322 & 3.82 & 46.345 & 62.57 & 1 & 2 \\
\hline 14 & 218.340 & 4.92 & 13.877 & 61.66 & 0 & 1 \\
\hline 15 & 234.339 & 4.53 & 32.595 & 62.31 & 1 & 2 \\
\hline 16 & 275.392 & 3.82 & 34.692 & 65.86 & 1 & 3 \\
\hline 17 & 274.282 & 4.67 & 34.561 & 61.72 & 1 & 1 \\
\hline 18 & 234.339 & 4.35 & 20.619 & 62.30 & 0 & 1 \\
\hline 19 & 224.275 & 3.91 & 34.539 & 59.54 & 1 & 1 \\
\hline 20 & 222.303 & 4.27 & 14.449 & 60.61 & 0 & 1 \\
\hline
\end{tabular}

\subsection{Molecular docking studies}

Molecular docking of ibuprofen and its modified derivatives with the target protein, salicylate bounded human cyclooxygenase-2 was performed (Table 4). Amongst all the modified derivatives, compounds 7, 16, 11 and 17 had higher docking score of -7.203 $\mathrm{kcal} / \mathrm{mol},-7.030 \mathrm{kcal} / \mathrm{mol},-6.976 \mathrm{kcal} / \mathrm{mol}$ and -6.876 $\mathrm{kcal} / \mathrm{mol}$ than ibuprofen and other derivatives. Compound 7 showed conventional hydrogen bonding with ASN382 amino acid residue from its carbonyl group and the delocalized electron in the benzene ring of the compound form a $\pi-\pi$ stacking with HIS207 amino acid residue from its amine group as shown in (figure 4a). Also, compound 16 (figure 4c) showed conventional hydrogen bonding interaction with HIE388 amino acid residue from its amine group, and the delocalized electron in benzene ring exhibited $\pi-\pi$ stack interaction with THR385 amino acid residue. Compound 11 (figure 4b) also exhibited hydrogen bonding interaction with PHE210 and ASN386 amino acid residue from its carbonyl and amine group and also showed $\pi-\pi$ stacking with HIS207 and HIS386 amino acid residue. Compound 17 (figure 4d) showed hydrogen bonding interaction with HIS207 amino acid from its carbonyl and $\pi-\pi$ stacking also occurred between the delocalized electron in benzene ring and HIS207, HIE388 amino acid residue. Similar interaction of drug candidates or NSAIDS with these amino acid residues of $5 \mathrm{~F} 1 \mathrm{~A}$ has been reported in literature [34-37]. All compounds have higher binding affinity than ibuprofen $(-5.846 \mathrm{kcal} / \mathrm{mol})$ except compounds $18(-5.583 \mathrm{kcal} / \mathrm{mol})$ and $20(-5.816$ $\mathrm{kcal} / \mathrm{mol}$ ) which showed lower binding affinity than ibuprofen. The negative values of the binding affinity suggest the spontaneity of the interaction of the ibuprofen derivatives with the COX-2 receptor. Also, similar interaction mechanisms are observed between compounds 7, 11, 16, 17 and ibuprofen. The interactions of other compounds and ibuprofen are presented in figures S17-S33. 


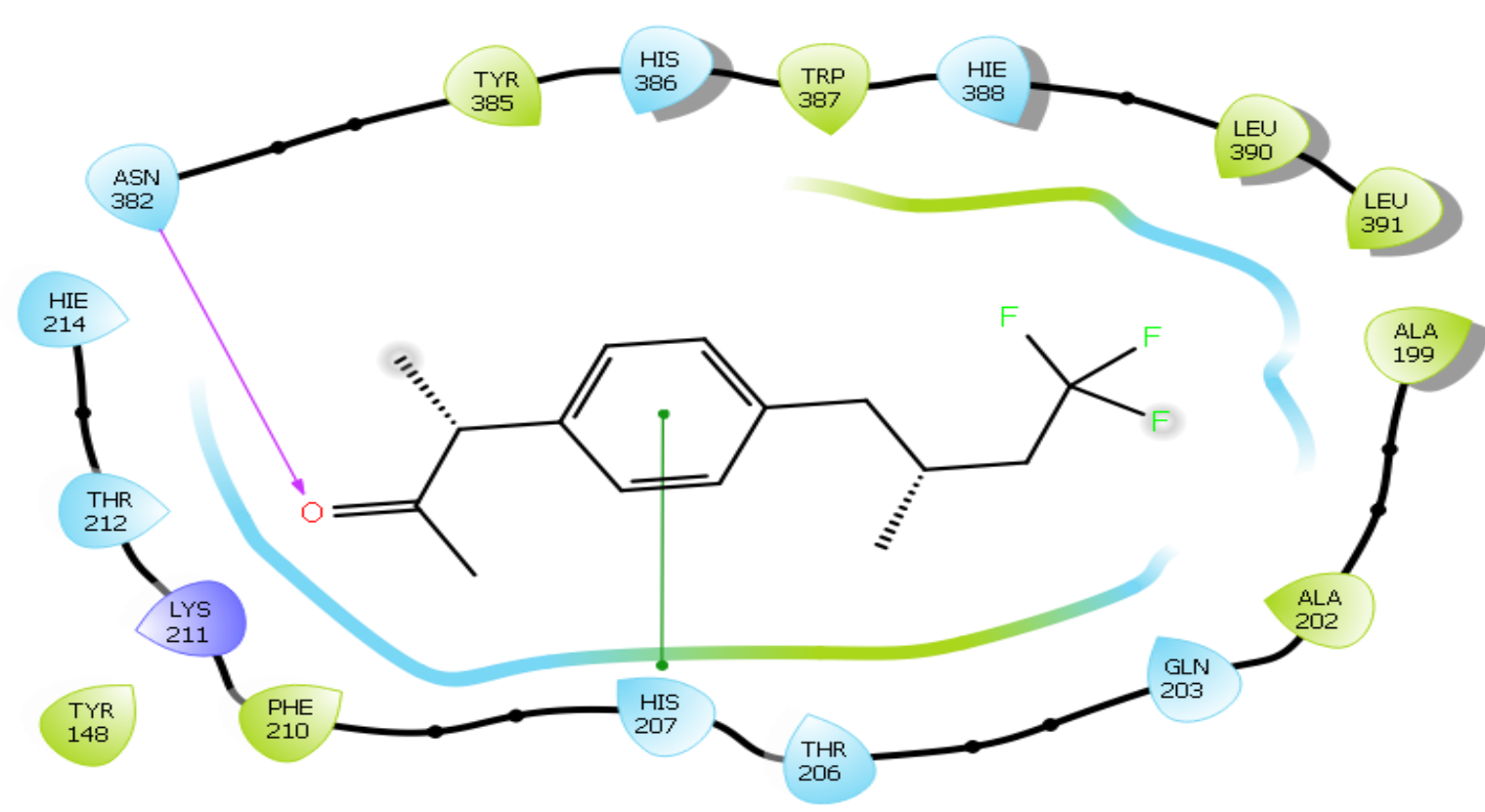

Figure 4a: Compound 7 with 5F1A

Table 4: Binding affinity and interaction type between the compounds and the receptor

\begin{tabular}{|c|c|c|c|}
\hline Compounds & $\begin{array}{c}\text { Binding } \\
\text { affinity } \\
(\mathrm{kcal} / \mathrm{mol})\end{array}$ & Amino acid & Interaction \\
\hline 1 & -6.914 & $\begin{array}{l}\text { ASN382, PHE210, } \\
\text { HIS386, HIS207 }\end{array}$ & Conventional hydrogen bond, $\pi-\pi$ stacking \\
\hline 2 & -5.95 & HIE388, HIS207 & Conventional hydrogen bond, $\pi-\pi$ stacking \\
\hline 3 & -6.607 & ASN386 & Conventional hydrogen bond \\
\hline 4 & -6.47 & HIS386, HIE388 & Conventional hydrogen bond \\
\hline 5 & -6.798 & HIE388 & Conventional hydrogen bond \\
\hline 6 & -6.533 & $\begin{array}{l}\text { THR212, PHE210, } \\
\text { HIS207, HIS386 }\end{array}$ & Conventional hydrogen bond, $\pi-\pi$ stacking \\
\hline 7 & -7.203 & ASN382. HIS207 & Conventional hydrogen bond, $\pi-\pi$ stacking \\
\hline 8 & -6.531 & GLN203, HIE388 & Conventional hydrogen bond, $\pi-\pi$ stacking \\
\hline 9 & -6.639 & $\begin{array}{l}\text { HIS207, HIE388, } \\
\text { THR385 }\end{array}$ & Conventional hydrogen bond, $\pi-\pi$ stacking \\
\hline 10 & -6.58 & ASN386 & Conventional hydrogen bond \\
\hline 11 & -6.976 & $\begin{array}{l}\text { PHE210, ASN386, } \\
\text { HIS207, HIS386 }\end{array}$ & Conventional hydrogen bond, $\pi-\pi$ stacking \\
\hline 12 & -6.154 & HIS207, HIE388 & Conventional hydrogen bond, $\pi-\pi$ stacking \\
\hline 13 & -6.555 & HIE388, HIS207 & Conventional hydrogen bond, $\pi-\pi$ stacking \\
\hline 14 & -6.034 & HIS207 & $\pi-\pi$ stacking \\
\hline 15 & -6.545 & HIS207, ASN382 & Conventional hydrogen bond, $\pi-\pi$ stacking \\
\hline 16 & -7.03 & HIE388, THR385 & Conventional hydrogen bond, $\pi-\pi$ stacking \\
\hline 17 & -6.876 & HIS207, HIE388, & Conventional hydrogen bond, $\pi-\pi$ stacking \\
\hline 18 & -5.583 & HIS207 & $\pi-\pi$ stacking \\
\hline 19 & -5.977 & HIE388, HIS207 & Conventional hydrogen bond, $\pi-\pi$ stacking \\
\hline 20 & -5.816 & $\begin{array}{l}\text { ASN382, HIS207, } \\
\text { HIS386 }\end{array}$ & Conventional hydrogen bond, $\pi-\pi$ stacking \\
\hline ibuprofen & -5.846 & HIE388, HIS207 & Conventional hydrogen bond, $\pi-\pi$ stacking \\
\hline
\end{tabular}




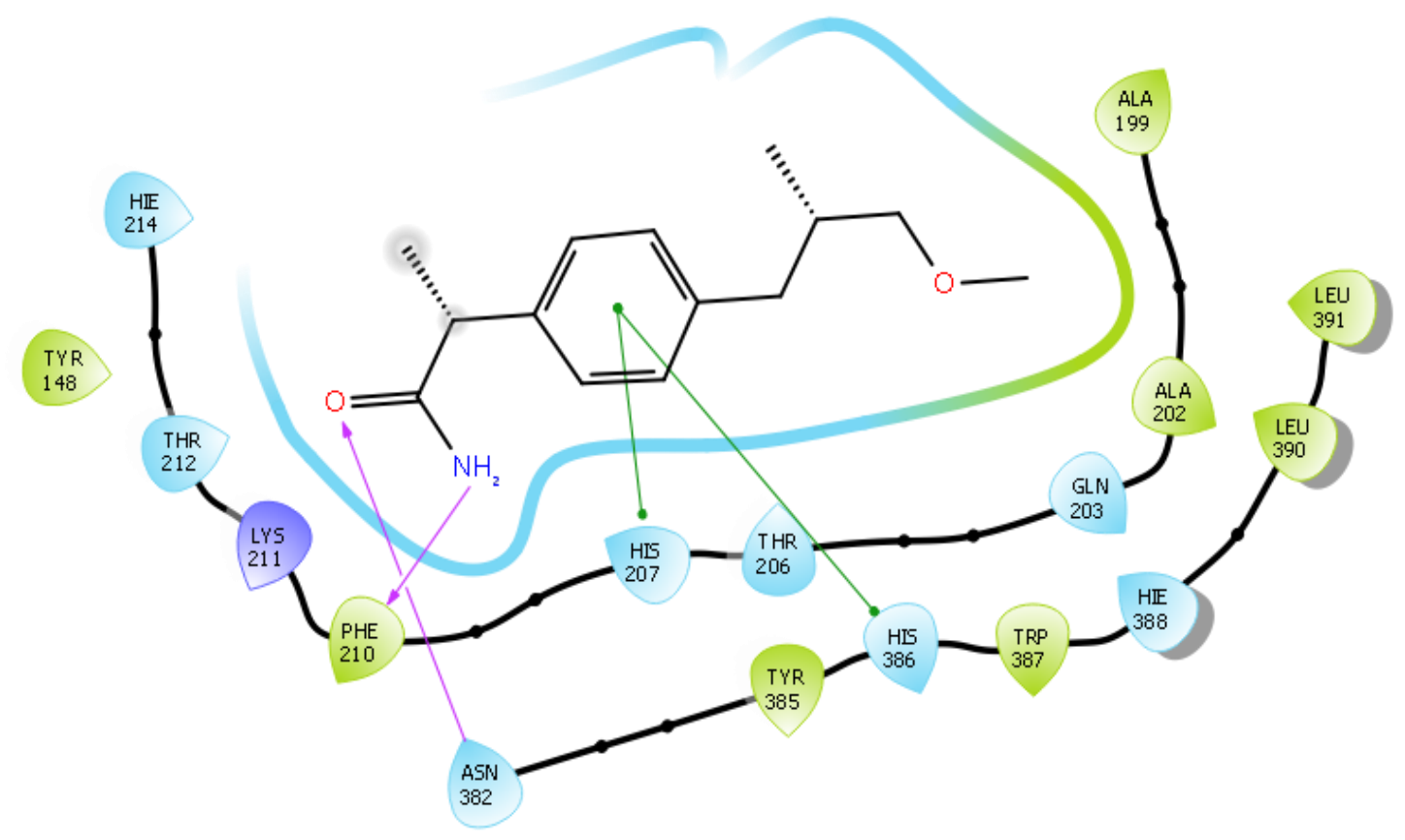

Figure 4b: Compound 11 with 5F1A

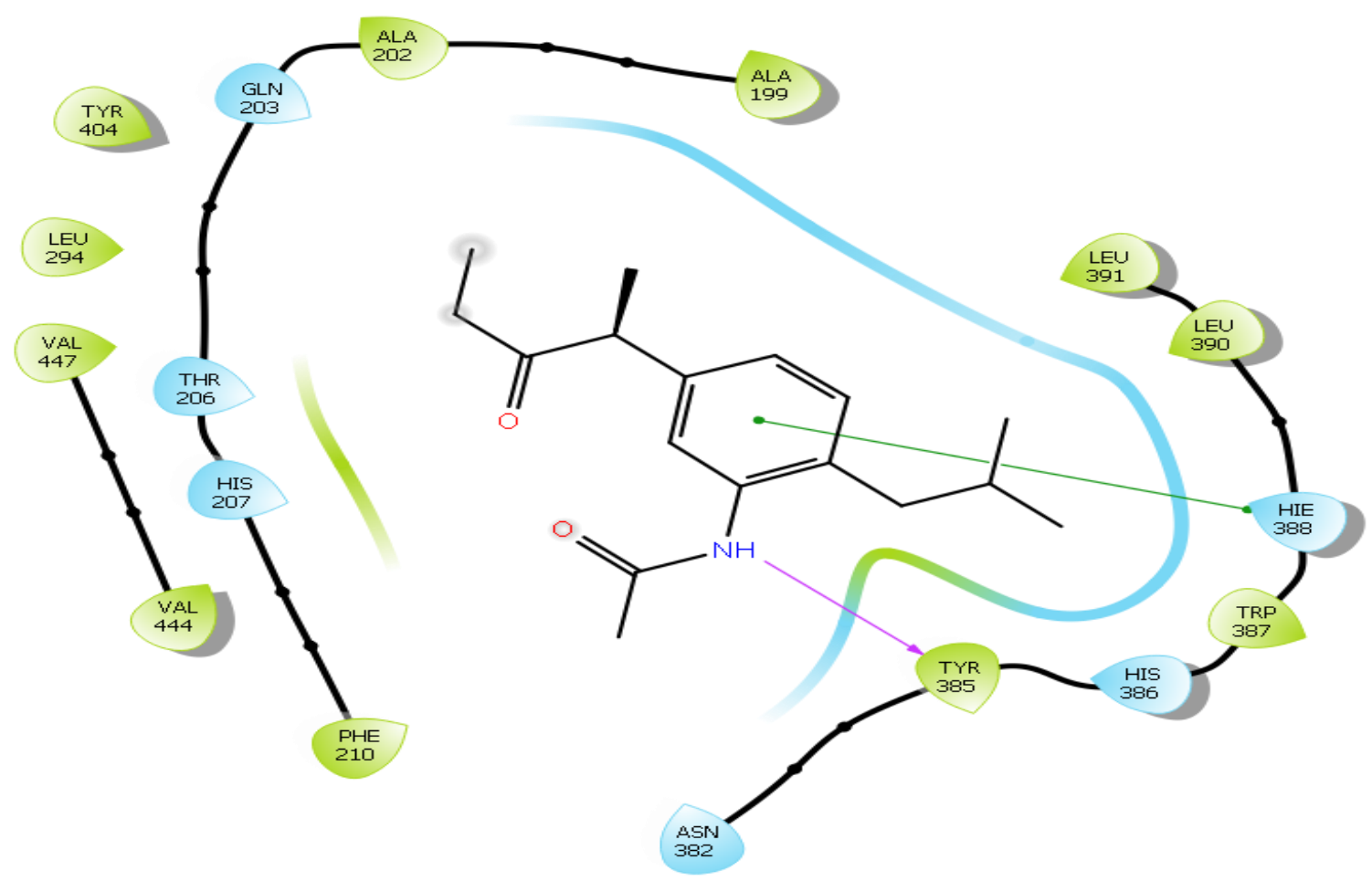

Figure 4c: Compound 16 with 5F1A 


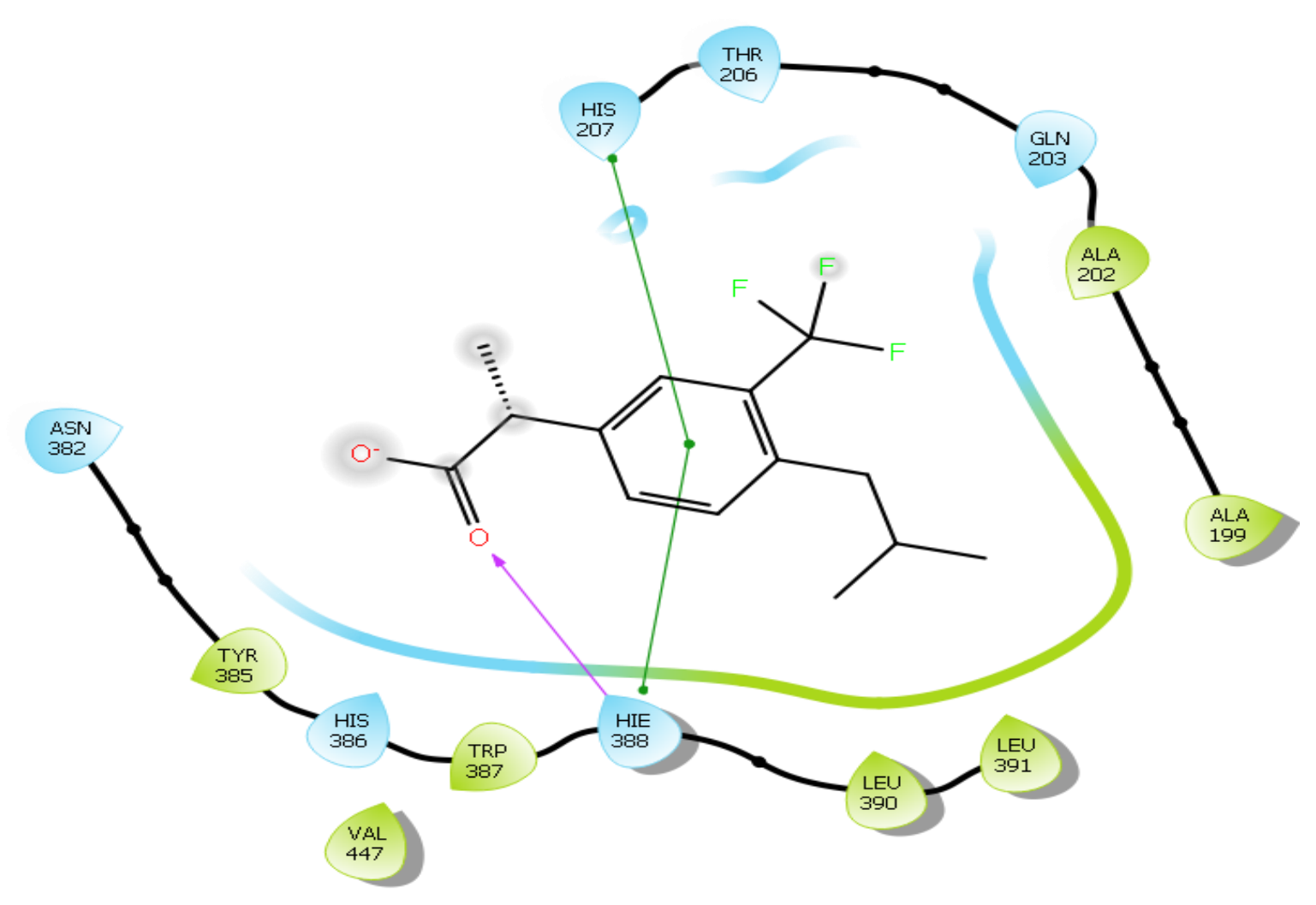

Figure 4d: Compound 17 with 5F1A

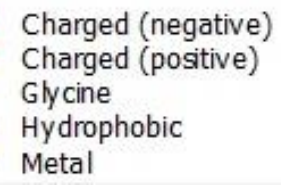

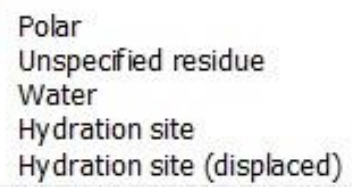

\author{
- Salt bridge \\ Solvent exposure
}

\subsection{Pharmacokinetics studies}

Many setbacks during drug development are related to poor pharmacokinetics. Therefore, monitoring the pharmacokinetic properties at early stage of drug discovery and development reduces the pharmacokinetics related problems. Pharmacokinetics properties which include GI absorption, BBB permeant, P-gp substrate, cytochrome P (CYP) 450 isoforms inhibitor and skin permeation $(\log \mathrm{Kp})$ were computed as shown in Table 5. The pharmacokinetics properties showed that all the modified compounds could be absorbed by human intestine. Cerebrospinal fluid barrier and Blood brain barrier (BBB) are the main interface separating the central nervous system and blood circulation. BBB permeation is a crucial property in drug development and discovery. BBB permeation predicts if a compound will cross over the $\mathrm{BBB}$ and exert its therapeutic effects on the brain [38]. The BBB permeation result showed that all the modified compounds have the ability to cross the BBB. Permeability glycoprotein (P-gp) is an important protein of the cell membrane that convey drug away from cell membrane and cytoplasm which leads to further metabolism and clearance of the molecule thereby enhancing the therapeutic failure due to the reduction in drug concentration [38]. The results showed that none of the compounds is a substrate for $\mathrm{P}$-gp. Cytochrome $\mathrm{P}_{450}$ play a crucial role in drug metabolism and clearance in the liver, and some of the isoforms are CYP1A2, CYP2C19, CYP2C9, CYP2D6 and CYP3A4. It is used in checking the drug-drug interaction which might have been caused by the inhibition of Cytochrome $\mathrm{P}_{450}$ isoforms and results to failure in co-administered drug metabolism thereby accumulating to toxic level [39]. Some of the compounds inhibited CYP2D6 and CYP3A4 isoform. Furthermore, the skin permeate $(\log K \mathrm{p})$ is also a vital property in the pharmaceutical company to determine the danger of compounds in case there is accidental contact with skin. The more negative the $\log K \mathrm{p}$, the less skin permeate is the molecule [40]. All the compounds are poorly permeable to skin. 
Table 5: Some selected pharmacokinetics properties of the compounds

\begin{tabular}{llllllllll}
\hline Compound & GI & BBB & P-gp & CYP1A2 & CYP2C19 & CYP2C9 & CYP2D6 & CYP3A4 & Log \\
& absorption & permeant & substrate & inhibitor & inhibitor & inhibitor & inhibitor & inhibitor & Kp(cm/s)
\end{tabular}

\begin{tabular}{llllllllll}
\hline Ibuprofen & High & Yes & No & No & No & No & No & No & -5.07 \\
1 & High & Yes & No & No & No & No & No & No & -5.53 \\
2 & High & Yes & No & No & No & No & No & No & -4.92 \\
3 & High & Yes & No & No & No & No & Yes & No & -5.48 \\
4 & High & Yes & No & No & No & No & Yes & No & -5.56 \\
5 & High & Yes & No & No & No & No & No & No & -4.99 \\
6 & High & Yes & No & No & No & No & Yes & No & -5.88 \\
7 & High & Yes & No & No & No & No & No & Yes & -4.67 \\
8 & High & Yes & No & No & No & No & No & No & -5.66 \\
9 & High & Yes & No & No & No & No & No & No & -5.61 \\
10 & High & Yes & No & Yes & No & No & No & No & -6.30 \\
11 & High & Yes & No & No & No & No & No & No & -6.17 \\
12 & High & Yes & No & No & No & No & Yes & No & -5.59 \\
13 & High & Yes & No & No & No & No & No & No & -5.52 \\
14 & High & Yes & No & No & No & No & Yes & No & -4.66 \\
15 & High & Yes & No & No & No & No & Yes & No & -5.02 \\
16 & High & Yes & No & No & No & No & Yes & Yes & -5.60 \\
17 & High & Yes & No & No & No & No & No & No & -4.83 \\
18 & High & Yes & No & No & No & No & Yes & No & -4.75 \\
19 & High & Yes & No & No & No & No & No & No & -4.74 \\
20 & High & Yes & No & No & No & No & Yes & No & -4.76 \\
\hline
\end{tabular}

\section{CONCLUSIONS}

Drug likeness, physico-chemical and pharmacokinetic properties of twenty derivatives of a non-steroidal antiinflammatory drug (ibuprofen) have been investigated using computational approach. The compounds are capable of nucleophilic and electrophilic interactions with the active sites of the cyclooxygenase- 2 receptor with comparable chemical reactivity with the standard. The reactivity indices suggest that compound 13 exhibits exceptional reactivity. The compounds exhibit comparable affinity for and intermolecular interactions with the COX-2 receptor as that of the ibuprofen (standard) which may be attributed to the asymmetrical charge distribution in their molecular geometry. They are adequately lipophilic, could permeate the cell membrane and blood brain barrier, and inhibit some isoforms of Cytochrome $\mathrm{P}_{450}$ (CYP2D6, CYP3A4 and CYP1A2). These suggest their effective antiinflammatory potentials. Compound 10 displayed a preferential interaction with CYP1A2 inhibitor. The interaction of the potential drug candidates with active sites of the 5F1A receptor is majorly through the heteroatoms and $\pi$-electron system. The $\pi$-electron rich imidazole ring of His207 possibly contributes significantly to the $\pi-\pi$ stacking interactions with aromatic center of ibuprofen derivatives. The poor skin permeability of the drug candidates suggests gradual assimilation of the active ingredient for effective epicutaneous topical anti-inflammatory or analgesic actions.

\section{FUNDING}

The authors for this research did not receive any funding concerning this research.

\section{DECLARATION OF COMPETING INTEREST}

The authors declare that they have no known competing financial interests or personal relationships that could have appeared to influence the work reported in this paper. 


\section{ACKNOWLEDGEMENT}

Authors would like to thank Adekunle Ajasin University, Nigeria and the University of Ibadan, Nigeria for creating enabling environments for this research work.

\section{REFERENCES}

[1] https://my.clevelandclinic.org/health/drugs/1108 6-non-steroidal-anti-inflammatory-medicinesnsaids.

[2] https://www.betterhealth.vic.gov.au/health/condit ionsandtreatments/medications-non-steroidalanti-inflammatory-drugs.

[3] Ho, K.Y., Gwee, K.A., Cheng, Y.K., Hoon, K.H., Hee, H.T., et al. (2018). Nonsteroidal antiinflammatory drugs in chronic pain: implications of new data for clinical practice. Journal of Pain Research. 11, 1937-1948.

[4] Simmons, D.L., Wagner, D., Westover, K. (2000). Nonsteroidal Anti-Inflammatory Drugs, Acetaminophen, Cyclooxygenase 2, and Fever. Clinical Infectious Diseases. 31, 211-218. doi: 10.1086/317517.

[5] Vishwakama, R.K., Negi, D.S. (2020). The Development of COX-1 and COX-2 Inhibitors: A Review. International Journal of Pharmaceutical Science and Research. 11(8), 3544-3555. doi: 10.13040/IJPSR.0975-8232.

[6] Bushra, R., Aslam, N. (2010). Review Article An Overview of Clinical Pharmacology of Ibuprofen. Oman Medical Journal. 25(3),155-161. doi: 10.5001/omj.2010.49.

[7] Kumar, P., Nimesh, S., Singh, S. (2020). Aryl Propionic Acid Derivatives: A Recent Advancement in Pharmacological Activities. International Journal of Pharmacy and Pharmaceutical Research. 17(4), 540-555.

[8] Rayburn, E.R., Ezell, S.J, Zhang, R. (2009). AntiInflammatory Agents for Cancer Therapy. Molecular and Cellular Pharmacoly. 1(1), 29-43. doi: 10.4255/mcpharmacol.09.05.

[9] https://www.nhsinform.scot/tests-andtreatments/medicines-and-medical-aids/types-of medicine/ibuprofen

[10] Onawole, A.T., Nasser, M.S., Hussein, I.A. (2021). Theoretical studies of methane adsorption on Silica-Kaolinite interface for shale reservoir application Applied Surface Science Theoretical studies of methane adsorption on Silica-Kaolinite interface for shale reservoir application. Applied Surface Science. 546, $149164 . \quad$ doi: 10.1016/j.apsusc.2021.149164.

[11] Ojo, N.D., Krause, R.W., Obi-Egbedi, N.O. (2020). Electronic and nonlinear optical properties of 3-(((2-substituted-4nitrophenyl)imino)methyl)phenol.

Compututational and Theoretical Chemistry 1192. doi: 10.1016/j.comptc.2020.113050.

[12] Ogunyemi, B.T., Oyeneyin, O.E., Esan, O.T., Adejoro, I.A. (2020). Computational modelling and characterisation of phosphole adopted in triphenyl amine photosensitisers for solar cell applications. Results in Chemistry 100069. doi: 10.1016/j.rechem.2020.100069.

[13] Yusuf, T.L., Oladipo, S.D., Olagboye, S.A., Zamisa, S.J., Tolufashe, G.F. (2020). Solvent-free synthesis of nitrobenzyl Schiff bases: Characterization, antibacterial studies, density functional theory and molecular docking studies. Journal of Molecular Structure. 128857. doi: 10.1016/j.molstruc.2020.128857.

[14] Adejoro, I.A., Waheed, S.O., Adeboye, O.O., Akhigbe, F.U. (2017). Molecular Docking of the Inhibitory Activities of Triterpenoids of Lonchocarpus cyanescens against Ulcer. Journal of Biophysical Chemistry 8, 1-11. doi: 10.4236/jbpc.2017.81001.

[15] Olanrewaju, A.A., Ibeji, C.U., Oyeneyin, O.E. (2020). Biological evaluation and molecular docking of some newly synthesized $3 \mathrm{~d}$-series metal(II) mixed-ligand complexes of fluoronaphthyl diketone and dithiocarbamate. SN Applied Sciences. 2(4), 678. doi: 10.1007/s42452020-2482-0.

[16] Kumar, A., Satya, M., Tewari, P. (2020). Density functional theory calculations of spectral, NLO, reactivity, NBO properties and docking study of Vincosamide-N-Oxide active against lung cancer cell lines H1299. SN Applied Sciences. 2,1021. doi: 10.1007/s42452-020-2842-9.

[17] Oyebamiji, A.K., Semire, B. (2016). Studies of Anti-Hypertensive Activity of 1,4Dihydropyridine Derivatives: Combinations of DFT-QSAR and Docking Approaches. Bulletin of Pharmaceutical Research. 6(3), 105-13. doi: 10.21276/bpr.2016.6.3.4.

[18] Bittencourt, J.A.H.M., Neto, M.F.A., Lacerda, P.S., Bittencourt, R.C.V.S., Silva, R.C., Lobato, C.C., Silva, L.B., Leite, F.H.A., Zuliani, J.P., Rosa, J.M.C., Borges, R.S., Santos, C.B.R., (2019). In silico evaluation of ibuprofen and two benzoylpropionic acid derivatives with potential anti-inflammatory activity. Molecules 24. https://doi.org/10.3390/molecules24081476

[19] Chebrolu, A., Madhavan, S., (2020). Molecular docking study of ibuprofen derivatives as selective inhibitors of cyclooxygenase-2. International Journal of Pharmaceutical Sciences and Research. 11, 6526-6531. https://doi.org/10.13040/IJPSR.09758232.11(12).6526-31

[20] Becke, A.D. (1993). Density-functional thermochemistry. III. The role of exact exchange. Journal of Chemical Physics. 98(7), 5648-5652. doi: 10.1063/1.464913.

[21] https://www.rcsb.org/structure/5F1A

[22] Sastry, W., Adzhigirey, G.M., Day, M., Annabhimoju, T., Sherman, R. (2013). Protein and ligand preparation: parameters, protocols, and influence on virtual screening enrichments. 
Journal of Computer Aided Molecular Design. 27, 221-234. doi: 10.1007/s10822-013-9644-8.

[23] Shelley, J.C., Cholleti, A., Frye, L., Greenwood, J.R., Timlin, M.R., Uchimaya, M. (2007). Epik: a software program for $\mathrm{pK}$. Journal of Computer Aided Molecular Design. 21, 681-691. doi: 10.1007/s10822-007-9133-z.

[24] Shivakumar, D., Williams, J., Wu, Y., Damm, W., Shelley, J. et al (2010). Prediction of absolute solvation free energies using molecular dynamics free energy perturbation and the opls force field. Journal of Chemical Theory and Computation. 6(5), 1509-1519. doi: 10.1021/ct900587b.

[25] Friesner, R.A., Murphy, R.B., Repasky, M.P., Frye, L.L. (2006). Greenwood JR et al. Extra precision glide: docking and scoring incorporating a model of hydrophobic enclosure for protein-ligand complexes. Journal of Medicinal Chemistry. 49(21), 6177-6196. doi: 10.1021/jm0512560.

[26] https://www.Swissadme.ch

[27] Shyma, M.Y., Sheena, M.Y., Resmi, K.S., Thomas, R. (2019). DFT and molecular docking investigations of oxicam derivatives. Heliyon. 5(7), e02175. doi: 10.1016/j.heliyon.2019.e02175.

[28] Hazhazi, H., Melkemi, N., Bouachrine, M. (2019). DFT-based reactivity and combined QSAR, molecular docking of 1,2,4,5-Tetrazine derivatives as inhibitors of Pim-1 kinase. Heliyon. 5, 0-9. 10.1016/j.heliyon.2019.e02451.

[29] Das, D., Kumar, A., Guruprasad, R., Mahapatra, D.K. (2016). Molecular Docking and Density Function Theory (DFT) Studies of some 4-( 2Chloroacetamido) Benzoic Acid Derivatives as Local Anesthetics. Molecular Modeling. 2017, 15.

[30] Targema, M., Obi-Egbedi, N.O., Adeoye, M.D. (2013). Molecular structure and solvent effects on the dipole moments and polarizabilities of some aniline derivatives. Computional and Theoretical Chemistry. 1012, 47-53. doi: 10.1016/j.comptc.2013.02.020.

[31] Tanak, H., Ağar, A.A., Büyükgüngör, O. (2014). Experimental (XRD, FT-IR and UV-Vis) and theoretical modeling studies of Schiff base (E)N'-((5-nitrothiophen-2-yl)methylene)-2phenoxyaniline. Spectrochimica Acta - Part A Molecular and Biomolecular Spectroscopy. 118, 672-682. doi: 10.1016/j.saa.2013.08.054.
[32] Lipinski, C.A., Lombardo, F., Dominy, B.W., Feeney, P.J. (1997). Experimental and computational approaches to estimate solubility and permeability in drug discovery and development settings. Advanced Drug Delivery Reviews. 23(1-3), 3-25. doi: 10.1016/s0169409x(00)00129-0.

[33] Clark, D.E. (1999). Rapid Calculation of Polar Molecular Surface Area and Its Application to the Prediction of Transport Phenomena.1. Prediction of Intestinal Absorption. Journal of Pharmaceutical Sciences. 88(8), 807-814. doi: 10.1021/js9804011.

[34] Beura, S., Chetti, P., (2020). Identification of potential human COX-2 inhibitors using computational modeling and molecular dynamics simulations. Journal of Molecular Structure. 1216 , $1-10$. https://doi.org/10.1016/j.molstruc.2020.128271

[35] Veena, B.S., Sujatha, E., (2019). In silico molecular docking studies of isolated phytochemicals from the Ledebouria genes as COX-2 inhibitors. Journal of Pharmacognosy and Phytochemistry. 8, 2231-2235.

[36] Yadav, T.C., Kumar, N., Raj, U., Goel, N., Vardawaj, P.K., Prasad, R., Pruthi, V., 2020. Exploration of interaction mechanism of tyrosol as a potent anti-inflammatory agent. Journal of Biomolecular Structure and Dynamics. 38, 382397. https://doi.org/10.1080/07391102.2019.1575283

[37] Uzzaman, M., Mahmud, T., (2020). Structural modification of aspirin to design a new potential cyclooxygenase (COX-2) inhibitors. In Silico Pharmacology. 8, 1-14. https://doi.org/10.1007/s40203-020-0053-0

[38] Geldenhuys, W.J., Mohammad, A.S., Adkins, C.E., Lockman, P.R. (2015). Molecular determinants of blood-brain barrier permeation. Therapeutic Delivery. 6, 961-971.

[39] Hollenberg, P.F. (2002). Characteristics and Common Properties of Inhibitors, Inducers and Activators of Cyp Enzymes. Drug Metabolism Reviews. 34(1-2), 17-35. doi: 10.1081/dmr120001387.

[40] Hadgraft, J., Lane, M.E. (2005). Skin permeation: The years of enlightenment. International Journal of Pharmarceutics. 305, 2-12. doi: 10.1016/j.ijpharm.2005.07.014. 